\title{
A distributional theory of government growth
}

Strulik, Holger

Publication date:

2004

Document version

Early version, also known as pre-print

Citation for published version (APA):

Strulik, H. (2004). A distributional theory of government growth. Department of Economics, University of Copenhagen. 


\title{
DISCUSSION PAPERS Institute of Economics University of Copenhagen
}

$$
\text { 04-26 }
$$

A Distributional Theory of Government Growth

\author{
Holger Strulik
}

Studiestræde 6, DK-1455 Copenhagen K., Denmark

Tel. +45 35323082 - Fax +4535 323000

http://www.econ.ku.dk 


\title{
A Distributional Theory of Government Growth*
}

\author{
Holger Strulik ${ }^{\dagger}$
}

September 2004

This paper presents a closed form solution for time-consistent taxation and public spending in a dynamic game between government and median voter. Extending Meltzer and Richard's static analysis of government size the paper offers a theory of growth of government. At low stages of economic development the median voter, identified as a relatively poor worker, prefers to have no or only small redistributive taxation in order to foster savings. Through this channel he expects improvements of his labor productivity and wage. At higher stages of development, however, when capital is relatively abundant and prospects of further labor productivity gains through capital accumulation are smaller, the incentive to tax and redistribute income rises. Yet, in line with previous work on growth and infrastructure spending the median voter prefers a constant share of productive public spending at all times. Hence, government growth is solely driven by an expanding welfare state.

Keywords: Redistribution, Government Growth, Markov-Perfect Equilibrium. JEL: E6, H21, O40.

\footnotetext{
${ }^{*}$ I would like to thank Christian Groth, Ines Lindner, Nikolaus Siegfried, and participants at the Institute of Public Finance Annual Conference, Prague 2003 and at the European Economic Association Annual Conference, Stockholm 2003 for useful comments.

${ }^{\dagger}$ Institute of Economics, University of Copenhagen, Studiestraede 6, 1455 Copenhagen K, Denmark, email: holger.strulik@econ.ku.dk.
} 


\section{Introduction}

Alan Meltzer and Scott Richard's (1981) paper "A Rational Theory of the Size of Government" constitutes one of the seminal and most heavily cited publications in the literature about the redistributional state and its development over time. Meltzer and Richard show that a government striving for re-election will use a positive tax on income to finance lump sum transfers if the median voter earns less than average income. Defining the share of income redistributed as a measure of the size of government they show that government size increases with decreasing income of the median voter. Lower income of the median voter may originate from an increasing spread of the franchise as observed in many countries over the last centuries so that their model can explain expansion of the government sector during that period of time. Because results are derived in a general equilibrium setting with optimizing agents Meltzer and Richard refer to their work as a "a rational theory of the size of government with contrast to older, more ad-hoc explanations of the same phenomenon like Wagner's Law and Baumol's cost disease (Wagner, 1893, Baumol, 1967).

Although Meltzer and Richard frequently refer to an expansion of the government sector over time, their theory is in fact static. They conclude (p. 925): "[I]t seems necessary to embed the analysis in a model with saving, capital accumulation, and public goods and to explore the effect of permitting relative shares to change as income changes. From an analysis of a growing economy, we can expect to develop a rational theory of the growth of government to complement our analysis of the government's size."

This paper offers such an extension towards a theory of government growth. It considers an economy populated by investors in capital, workers with varying productivity (i.e. labor income), and a government that uses a general income tax in order to finance productive government spending and lump sum transfers. It explains why in such an environment the size of government is increasing with decreasing labor income of the median voter (which

confirms Meltzer and Richard's result) and why the government share of GDP increases as the economy grows (which constitutes the new result).

The main difficulty in developing a theory of government growth i.e. of time-dependent fiscal policy is the problem of time-inconsistency (Chamley, 1986). A convincing theory of government growth should therefore consider policy strategies that do not depend on credibility but 
on the state of the economy. Unfortunately, closed form solutions under such time-consistent Markovian strategies are hard to find. The solution derived in this paper requires logarithmic utility, inelastic labor supply, and a society divided in capital owners and workers. Numerical solutions, however, show robustness of the result with respect to general iso-elastic utility functions.

The article is built upon Judd (1985) who has investigated open-loop redistributive taxation in a neoclassical worker-capitalists economy and, in particular, upon Kemp et al. (1993) who have studied time-consistent taxation in this framework. It extends the literature by distinguishing between productive public spending and redistribution (i.e. the provision of a welfare state) and by deriving adjustment dynamics for time-consistent taxation and redistribution. ${ }^{1}$

The empirical literature provides ample evidence that the share of government in GDP has grown significantly in all western countries over the last century (see e.g. Borcherding, 1985). In particular the results presented in Boix (2001) support the model developed in this present paper by showing that both income per capita and income inequality have an independent influence on the size of government (See also Husted and Kenny, 1997). Yet, some qualifying remarks are in order. First, there are also quite a few studies who were unable to find a positive correlation between income inequality and redistribution, most notably Perotti (1996). Section 5 offers an explanation - built upon cross-country intersections of policy functions for how both positive and negative correlations can be observed within the same politicoeconomic model. Second, government size has stagnated or even decreased over the last two decades for some fully developed countries. While the model explains a stagnating expansion of government as completed convergence towards the steady-state it fails to explain its secular decrease. The appropriate period that one should have in mind when reading this paper are therefore the three decades after World War II where both income per capita and government share of GDP grew at high rates in most parts of the western world.

\footnotetext{
${ }^{1}$ Politico-economic aspects of taxation are also investigated by Romer (1975), and Roberts (1977), and in an endogenous growth framework among others by Bertola (1993), Alesina and Rodrik (1994), Persson and Tabellini (1994), and Krusell et al. (1997). Recently, Hassler et al. (2003) have also provided analytical results for Markov equilibria of voting on redistributive taxation. Their article, however, considers survival of the welfare state, i.e. conditions for it's long-run existence, while the present work focusses on growth of the welfare state, i.e. it's development over time.
} 


\section{A Politico-Economic Model of Government Growth}

We consider an economy whose output $(y)$ is produced by competitive firms using labor supplied by workers and capital supplied by capitalists. A worker $i \in[0,1]$ has productivity $\epsilon_{i}$, where the continuous distribution of productivities (or skills) is normalized so that average

productivity is unity; $\int_{0}^{1} \epsilon_{i} \mathrm{~d} i=1$. The average wage rate is denoted by $w$. Workers supply one unit of labor and earn an income according to their productivity level of $\epsilon_{i} w$. Production is subject to a Cobb-Douglas function with capital share $\alpha$ and general factor productivity $A$ implying an interest rate $r=\alpha A k^{\alpha-1}$ and an average wage $w=(1-\alpha) A k^{\alpha}$, where $k$ denotes the capital stock.

A democratically elected government taxes income at a rate $\tau$ and uses revenues for redistribution and productive spending. Its choice variables are the tax rate and the share of tax revenue spend productively, denoted by $q$. The tax rate is used as a measure of government size while the share of national income redistributed, given by $(1-q) \tau$, is used as a measure of the size of the welfare state. The worker with productivity $\epsilon_{m}$ is identified as the median voter. His preferences determine fiscal policy.

All citizens derive utility from consumption. While workers by definition consume all income, capitalists face the usual problem of allocating consumption optimally over time. An average capitalists consuming $c_{k}$ derives utility $\int_{0}^{\infty} u\left(c_{k}\right) \mathrm{e}^{-\rho t} \mathrm{~d} t$. He shares with all other citizens a time preference rate $\rho$ and an isoelastic utility function $u(x)=x^{1-\theta} /(1-\theta)$ with special case $u(x)=\ln (x)$ for $\theta=1$. His budget constraint is given by

$$
\dot{k}=(1-\tau) r k-\delta k-c_{k},
$$

where $\delta$ is the rate of depreciation. The solution of the utility maximization problem is characterized by the Ramsey rule $\dot{c}_{k} / c_{k}=[r(1-\tau)-\delta-\rho] / \theta$, i.e. the consumption strategy $c_{k}(k)$ fulfils

$$
c_{k}^{\prime}(k)=\frac{\dot{c}}{\dot{k}}=\frac{[r(1-\tau)-\delta-\rho] c_{k}}{\theta\left[r(1-\tau) k-\delta k-c_{k}\right]} .
$$

The part of tax revenues used for productive spending, $g=q \tau y$, enhances general factor productivity. As in Barro and Sala-i-Martin (1992) these enhancements are subject to congestion so that total factor productivity is obtained as $A=B(g / y)^{\beta}$. These congestion effects prevent that government expenditure generates perpetual growth although it is an essential 
input in production. Fiscal policy independent productivity $B$, could be used to introduce exogenous technological progress. Because this, however, would not add further insight into the mechanics behind government growth, we consider $B$ to be constant over time. The term $\beta$ determines effectivity of government spending. Rewrite production as $y=\left(B g^{\beta} k^{\alpha}\right)^{1 /(1+\beta)}$ to obtain the output elasticity of government expenditure as $\beta /(1+\beta)$. This expression will play a major role in the subsequent discussion.

Tax revenues not spent productively are used to redistribute income uniformly from capitalists to workers. Hence a worker $i$ has net income of

$$
c_{i}=(1-\tau)(1-\alpha) w \epsilon_{i}+\tau(1-q) y=\left[(1-\tau)(1-\alpha) \epsilon_{i}+\tau(1-q)\right] B(q \tau)^{\beta} k^{\alpha}
$$

Inserting the interest rate the equation of motion can be rewritten as

$$
\dot{k}=(1-\tau) \alpha B(q \tau)^{\beta} k^{\alpha}-\delta k-c_{k}
$$

Because infrastructure spending is an essential input in production, capitalists and workers irrespective of their productivity want the government to play a role in the economy (i.e. $\tau>0$ ). But only workers with sufficiently low productivity want to have a welfare state (i.e. they prefer $q<1$ ). Which policy is actually executed is determined by the median voter whose intertemporal utility is maximized by the government subject to (2) - (4) through Markovian fiscal policy strategies, $\tau(k), q(k)$. Summarizing, the government maximizes the current value Hamiltonian

$$
\begin{aligned}
H & =\frac{1}{1-\theta}\left\{\left[(1-\tau)(1-\alpha) \epsilon_{m}+(1-q) \tau\right] B(q \tau)^{\beta} k^{\alpha}\right\}^{1-\theta} \\
& +\lambda\left[(1-\tau) \alpha B(q \tau)^{\beta} k^{\alpha}-\delta k-c_{k}(k)\right]
\end{aligned}
$$

where $\epsilon_{m}$ denotes the median voter's productivity.

The solution of this Stackelberg game with the government as leader and the average capitalist as follower is derived in the Appendix. Equilibrium fiscal policy strategies fulfill the following set of equations.

$$
q \tau=\frac{\beta}{1+\beta}
$$




$$
\begin{aligned}
& \dot{\tau}=\frac{(1-\tau)(1-\alpha) \epsilon_{m}+\tau-\frac{\beta}{1+\beta}}{\theta\left[\left(1-(1-\alpha) \epsilon_{m}\right]\right.}\left\{\frac{\alpha^{2} A k^{\alpha-1}}{(1+\beta)\left[1-(1-\alpha) \epsilon_{m}\right]}-\delta-\rho-\frac{\partial c_{k}}{\partial k}-\theta \alpha \frac{\dot{k}}{k}\right\}, \\
& \dot{k}=(1-\tau) \alpha A k^{\alpha}-\delta k-c_{k}(k), \\
& 0=\lim _{t \rightarrow \infty} u^{\prime}\left(c_{m}\right)\left[1-(1-\alpha) \epsilon_{m}\right] / \alpha \cdot k \mathrm{e}^{-\rho t} .
\end{aligned}
$$

Inspection of (6) immediately yields a first result.

THEOREM 2.1. The GDP share of productive public services, $g / y=q \tau$, is time-invariantly and independently from characteristics of the median voter determined by the production elasticity of infrastructure.

The result generalizes Barro's (1990) "natural efficiency condition" that the optimal marginal return on productive expenditure equals unity $(\partial y / \partial g=\beta /(1+\beta) y / g=1)$ in two respects. First, it is derived as a dynamic Markovian strategy where fiscal policy instruments are not restricted to be constant over time. Second, it holds although individuals differ in productivity and although infrastructure expenditure is not the only objective of government. The possibility that income distribution policy changes over time, however, prevents to conclude a constant size of government from the natural efficiency condition.

Government size $\tau$ is generally not constant in (7) as long as the economy develops, i.e. as long $k$ grows. A solution trajectory of (7) - (9) and (2) provides an equilibrium tax strategy $\tau(k)$ together with an equilibrium consumption strategy $c_{k}(k)$. Because the partial derivative $c_{k}^{\prime}$ in (7) has generally no analytical representation we proceed in two steps. ${ }^{2}$ The next section considers the special case of logarithmic utility for which a simple closed form solution for $c_{k}(k)$ exists. Section 4 then investigates welfare state dynamics for the general iso-elastic utility case using numerical solutions of the model.

\section{Government Growth: Analytical Solution}

This section presents government dynamics for the analytically solvable case of logarithmic utility, i.e. $\theta=1$. Inspect (2) to verify that then the consumption strategy $c_{k}=\rho k$ is the solution of the capitalists' problem not only at the steady-state but at any conceivable state

\footnotetext{
${ }^{2}$ In order to avoid confusion I refer to the solution of the differential game as equilibrium, defined by equilibrium Stackelberg strategies for government and citizens, whereas a state of constant $k$ (and therewith constant fiscal policy) is referred as steady-state. Hence an equilibrium is obtained at any adjustment path towards the steady-state fulfilling (7)-(9) as well as in the steady-state itself.
} 
of the economy. This behavior originates from the fact that for logarithmic utility income and substitution effects of expected future fiscal policy changes exactly balance each other so that current net investment, $\dot{k}=(1-\tau) r k-(\delta+\rho) k$, depends only on current fiscal policy and the current state of the economy. This phenomenon is in detail derived and explained by Lansing (1999) and Krusell (2002). It is therefore worthwhile to know whether the results on the mechanics of government growth that will be derived in this section are not simply an artefact of the special properties of logarithmic utility. Using numerical techniques the next section confirms qualitatively similar government dynamics for the case of general iso-elastic utility functions.

The closed form solution for $c_{k}$ transforms (7) and (8) into an easily tractable two-dimensional system of ordinary differential equations.

$$
\begin{aligned}
& \dot{\tau}=\frac{(1-\tau)(1-\alpha) \epsilon_{m}+\tau-\frac{\beta}{1+\beta}}{\left[\left(1-(1-\alpha) \epsilon_{m}\right]^{2}\right.}\left\{\frac{\alpha^{2}}{(1+\beta)} k^{\alpha-1}-\left(\delta+2 \rho+\alpha \frac{\dot{k}}{k}\right)\left[1-(1-\alpha) \epsilon_{m}\right]\right\}, \\
& \dot{k}=(1-\tau) \alpha A k^{\alpha}-(\delta+\rho) k .
\end{aligned}
$$

From (6) follows that the equilibrium tax strategy is bounded from below, $\tau \geq \beta /(1+\beta)$ because the $q$ is per construction less than or equal to one. Hence, the numerator of the first term in (10) is always positive and the non-trivial steady-state of (10) and (11) is unique and obtained as follows.

$$
\begin{aligned}
& k^{*}\left(\epsilon_{m}\right)=\left\{\frac{(\delta+2 \rho)\left[1-(1-\alpha) \epsilon_{m}\right](1+\beta)}{\alpha^{2} A}\right\}^{\frac{1}{\alpha-1}}, \\
& \tau^{*}\left(\epsilon_{m}\right)=1-\frac{(\delta+\rho) \alpha}{(1+\beta)\left[1-(1-\alpha) \epsilon_{m}\right](\delta+2 \rho)} .
\end{aligned}
$$

Boundedness of $\tau$ from below also implies that there exists a corner solution without a welfare state at $q=1$. It is assumed when the median voter is very productive so that (13) is smaller than $\bar{\tau}^{*} \equiv \beta /(1+\beta)$ and $q$ would be larger than one according to (6). ${ }^{3}$ Summarizing, the actual steady-state fiscal policy is given by

$$
\tau^{*}=\max \left\{\bar{\tau}^{*}, \tau^{*}\left(\epsilon_{m}\right)\right\}
$$

\footnotetext{
${ }^{3}$ If the median voter is extremely rich the denominator in (13) gets negative suggesting a clearly suboptimal tax rate $\tau\left(\epsilon_{m}\right)$ larger than one. Of course, for this degenerate case the corner solution $\bar{\tau}^{*}$ also applies. In subsequent analyses I neglect this from the empirical viewpoint irrelevant case, i.e. I focus on $\epsilon_{m}<1 /(1-\alpha)$.
} 
At the corner, steady-state capital is obtained from (11) independently from the median voter's productivity as $\bar{k}^{*}=[(\delta+\rho)(1+\beta) /(\alpha A)]^{1 /(\alpha-1)}$. In order to compare corner and interior solution it is useful to focus on the empirically relevant case of a left-skewed income distribution, i.e. a median voter who earns less than (or at most the same as) average labor income, $\epsilon_{m} \leq 1$. Now note that $k^{*}\left(\epsilon_{m}\right)$ is increasing in $\epsilon_{m}$ and compare $k^{*}(1)$ with $\bar{k}^{*}$ to verify that steady-state capital and hence total income is lower if a welfare state exists. This is the familiar result of distortionary capital taxation: a welfare state requires higher tax rates which drives down the capitalists' incentive to invest.

Interestingly, the median voter - although per construction himself not an investor - is not necessarily interested in a welfare state. His indirect benefits from a high capital stock through high labor productivity and work income may overcompensate his direct benefits from income redistribution. A sufficient condition for a welfare state can be obtained by checking whether $\tau^{*}\left(\epsilon_{m}\right)$ is larger than $\bar{\tau}$ for a median voter with mean income. This yields the condition $\rho /(\delta+\rho)>\beta$. Only if time-preference is sufficiently high and infrastructure productivity is sufficiently low a citizen with mean income wants to have a welfare state at the steady-state. More generally, verify that the derivative $\partial \tau^{*}\left(\epsilon_{m}\right) / \partial \epsilon_{m}$ in (13) is negative which proves the following result.

TheOREM 3.1. The possibility that a welfare state exists and, if it exists, the size of the welfare state are decreasing in productivity (i.e. income) of the median voter.

Figure 1. Median Voter Income and Size of Welfare State
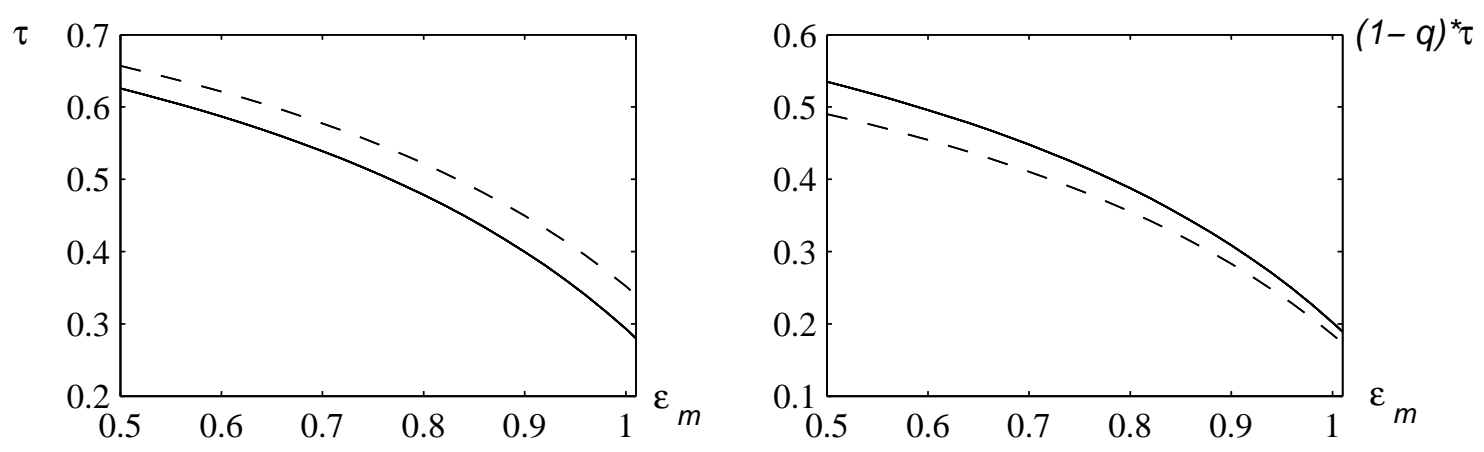

Parameters: $\alpha=0.36, \delta=0.05, \rho=0.02, B=1$. Solid lines: $\beta=0.1$, dashed lines: $\beta=0.2$ 
Figure 1 shows preferred tax rates (government size) on the left panel and GDP shares redistributed (welfare state size) on the right for parameters frequently used in calibration studies of the neoclassical growth model and alternative productivity of the median voter. One sees that any median voter poorer than the mean wants to have a welfare state. Empirically observable magnitudes for government size are obtained for $\epsilon_{m}$ between 0.75 and 1. Interestingly, for higher productivity of infrastructure - an increase of $\beta /(1+\beta)$ from 0.09 (solid lines) to 0.16 (dashed lines) - the median voter wants not only higher tax rates but also a smaller welfare state. Higher productivity of infrastructure leads to raising tax rates in order to provide more productive government services. This in turn raises productivity of all workers inclusive the median voter and reduces the wish for high taxes for the purpose of redistribution.

Comparative steady-state analysis replicates Meltzer and Richard's (1981) results with the same effects of rising income inequality and a spread of the franchise on the size of government and welfare state. Yet, the incentives that limit the size of government are slightly different. The median voter knows that higher tax rates reduce savings and investment and affect (1) his labor income through lower productivity on a less capital-intensively equipped working place and (2) total income in the economy that could be possibly redistributed. For that reason, even the poorest person with $\epsilon_{m}=0$ and no labor income at all would not support a tax rate of one hundred percent but "only" a $\tau^{*}$ of 0.74 .

While the results at the steady-state confirm Meltzer and Richard' s findings on size of government, the dynamic formulation of the present model allows to investigate growth of the welfare state which has not been possible within the earlier static framework. Recall that $\tau \geq \bar{\tau}^{*}$ to obtain the positively sloped $\dot{\tau}=0$-isocline.

$$
\tau=1-\frac{1}{\left[1-(1-\alpha) \epsilon_{m}\right](1+\beta)}+\frac{(\delta+\rho)(1-\alpha)+\rho}{\alpha^{2} A} \cdot k^{1-\alpha}
$$

Insert (11) in (10) to see that $\dot{\tau}>0$ above the curve and $\dot{\tau}<0$ below. The $\dot{k}=0$-isocline,

$$
\tau=1-\frac{\delta+\rho}{\alpha A} \cdot k^{1-\alpha}
$$

is negatively sloped with $\dot{k}<0$ above the curve and $\dot{k}>0$ below. Figure 2 shows the resulting phase diagram. The steady-state is identified as a saddle-point. 
Figure 2. Government Growth: Phase Diagram

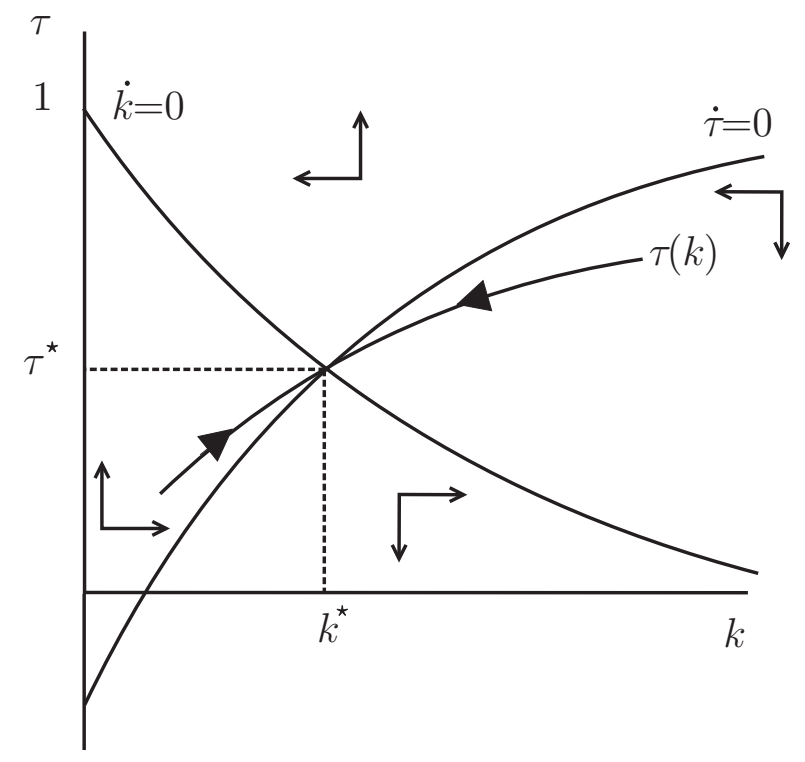

From the possible policy trajectories in Figure 2 only the stable manifold does not violate the first order conditions. All other paths cause the median worker's consumption to jump to zero in finite time either because of missing private capital $(k=0)$ or of missing infrastructure $(\tau=0)$. Hence, government dynamics are uniquely determined. The combined direction of motion points to the northwest for $k<k^{*}$ so that the stable manifold is upward sloping. Tax rates raise together with capital and hence together with GDP of the economy. From (6) follows that the income share of productive government spending stays constant over time implying that welfare expenditure rises superproportionally with income.

THEOREM 3.2. If a welfare state exists, its size increases as the economy grows.

For an intuition of the paper's main result, which holds irrespective of median voter's income, consider a developing economy far below its steady-state. At such a position of small capital stock a unit of net investment leads to pronounced improvements of labor productivity and current and future work income. High taxes for the purpose of redistribution would suppress savings and investment and largely reduce these future consumption possibilities. In other words, income redistribution causes comparatively large opportunity costs in form of low economic growth. Consequently, it is in the interest of the median voter that the government 
fosters savings and enhances growth with low tax rates and a small welfare state. At a stage of high development, however, the capital stock is close to its steady-state level and gains in labor productivity resulting from yet more investment are comparatively small. With not much growth to loose the opportunity costs of redistribution are comparatively small and the incentive to afford a large welfare state is large. ${ }^{4}$

Increasing inequality (measured by a reduction of the median voters productivity $\epsilon_{m}$ relative to the mean) raises the government's incentive to redistribute. It shifts the $\dot{\tau}=0$-curve upwards and leaves the $\dot{k}=0$-curve unchanged. This shifts the policy function $\tau(k)$ upwards implying a larger government and larger welfare state at the steady-state and along the adjustment path.

\section{Government Growth: General Case}

This paper has argued that the welfare state grows because opportunity costs of redistribution are higher at lower stages of development. The mechanism is based on the feature of decreasing marginal productivity and should be independent from the peculiarities of logarithmic utility. Nevertheless, in order to verify this claim we consider numerical solutions for alternative elasticities of marginal utility. From the Ramsey rule,

$$
\dot{c}_{k}=\frac{\left[(1-\tau) \alpha A k^{\alpha-1}-\delta-\rho\right] c_{k}}{\theta}
$$

evaluated at the steady-state follows $(1-\tau) \alpha A k^{\alpha}-\delta k=\rho k$ and hence with (8) the the familiar consumption rule $c(k)=\rho k$. With contrast to the log-utility case, however, the rule applies at the steady-state only.

Dynamic behavior off the steady-state is somewhat more complicated to assess because of the partial derivative $c_{k}^{\prime}$ in (7). We solve this problem by applying the backward integration technique described in Brunner and Strulik (2002). Using the initial guess $c_{k}^{\prime}=\rho$ the dynamic system (7), (8) and (13) is integrated backwards starting close to the steady-state. The derivative $c_{k}^{\prime}$ is simultaneously obtained according to (2). The backward integration technique employs the fact that any trajectory converges towards the stable manifold as time proceeds. Starting close to the steady-state, i.e. already close to the stable manifold, this procedure

\footnotetext{
${ }^{4}$ Because the argument is based on adjustment dynamics - driven by transitionally higher savings rates - it is
} robust against an extension of the model with TFP-driven growth. 
leads to very accurate approximations of the consumption function $c(k)$ and the equilibrium tax strategy $\tau(k)$.

Equilibrium tax rates for parameter values from Figure 1 and alternative values for the marginal elasticity of utility are shown in Figure 3. With re-reverted time the trajectories start at $k=2$ and end close to their respective steady-state value $k^{*}$. While tax policy is quite sensitive to changes of $\theta$, the main result that $\tau(k)$ is positively sloped remains valid for values of $\theta$ which are predominantly used in calibration of neoclassical growth models. Size of government and welfare state increase as the economy grows.

Figure 3. Policy Function for Alternative $\theta$

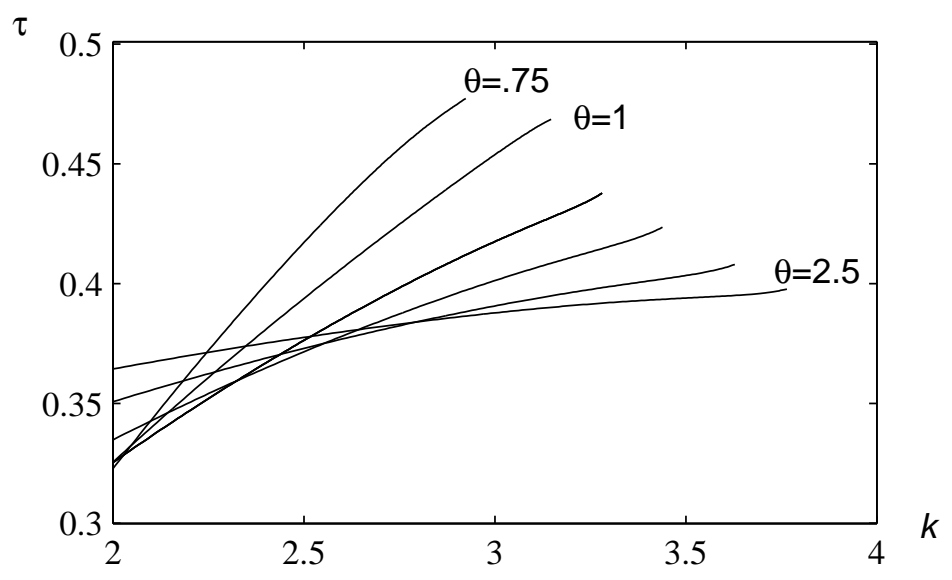

Parameters as in Figure 1 and $\epsilon_{m}=0.8, \theta \in[0.75,2.5]$.

Figure 3 also reveals that - in deviation to the standard tax-augmented neoclassical growth model - steady-state capital stock and hence total income depend on the marginal elasticity of utility. As in the standard model higher tax rates reduce the incentive to save and therewith long-run capital stock. Tax rates, however, are no longer fixed or set independently but determined by strategic interaction. The government takes into account the possible reaction of investors on their tax policy. The actual tax policy is adjusted to the magnitude of intertemporal income and substitution effects that a change of taxes, i.e. net interest rates, may provoke.

At the steady-state the incentive to tax is relatively small if the government faces citizens with strong preference to smooth consumption over time, characterized by a high value of $\theta$. 
In that case rising taxes would reduce investment considerably. For small values of $\theta$, however, the substitution effect is small and may be even dominated by the income effect (for $\theta<1$ ). Under these circumstances capitalists react to a further income loss through higher taxation by investing more in subsequent periods and the incentive to tax is relatively strong.

Far off the steady-state the opposite mechanism is at work. When capital is relatively scarce and interest rates are high, individuals with low $\theta$ are inclined to save much more than under steady-state conditions. In order to not distort the implied high growth potential the government taxes relatively little. If the government faces citizens with high $\theta$, on the other hand, it knows that their savings propensity at low stages of development does not much deviate from steady-state behavior. Because not much growth potential is lost, the government has an incentive to levy relatively high taxes right from the beginning.

In other words, size and growth of the welfare state are interrelated. Populated by individuals with low preference for consumption smoothing the economy and its government size converge relatively rapidly towards their steady-state. For example, initial growth $\left(\dot{c}_{m} / c_{m}\right)$ at $k=2$ is 5.2 percent for $\theta=1$ and 1.8 percent for $\theta=2.5$. For the same reason of a large intertemporal substitution effect, however, the high-growth economy approaches a lower steady-state income level: it's government is more inclined to afford a higher welfare state. The fact that size and growth of government depend on the state of the economy means that policy functions $\tau(k)$ for governments in alternative economies may intersect each other. The next section will use this feature to offer an explanation for the sometimes weak and counter-intuitive empirical findings on the correlation between income distribution and government size.

\section{Inequality and Government Size: A Theoretical Cross-Country Comparison}

The correlation between inequality and government size has been extensively investigated empirically. Interestingly, some studies (among others Perotti, 1996, and Benabou, 1996) are unable to support the theoretical argument that more unequal societies should have a larger government size. On the other hand, other studies find strong support (see e.g. Meltzer and Richard, 1983, Husted and Kenny, 1997, and Milanovic, 2000), and it is probably best to say that the problem is not yet completely resolved empirically. The theoretical literature has 
reacted to the mixed and inconclusive empirical results by extending the basic model so that it can explain also the opposite outcome, i.e. government size decreasing with inequality. ${ }^{5}$

The present paper offers an alternative explanation for the puzzling empirical findings. It is based on cross-country comparative dynamics and maintains a generally positive correlation between income inequality and government size within countries. Consider two countries distinguished by alternative levels of income inequality and one or more other parameter value so that their policy functions $\tau(k)$ intersect. Assume, for example, that for income levels smaller than at the point of intersection the more unequal country has a larger government (measured by $\tau$ ). Then, by construction, the opposite holds true after the intersection point: the less unequal country affords the larger government.

The last section has applied to varying preference parameters $(\theta)$ to show that policy functions may indeed intersect. For a cross-country comparison, however, it is more appealing to take preferences as being identical across countries and consider differences of general productivity which can be more convincingly justified by empirical evidence. ${ }^{6}$ As an example we consider one country characterized by lower general productivity and lower inequality $\left(\epsilon_{m}=0.8, B=1\right)$ than the other country $\left(\epsilon_{m}=0.6, B=1.3\right)$. All other country characteristics are identical. ${ }^{7}$ Here, we do not try to investigate why one country is more unequal or more productive than the other or whether these phenomena are correlated. We focus solely on the problem why under these circumstances researchers comparing both countries can arrive at different conclusions about inequality and government size.

Figure 4 shows the policy functions for both countries beginning far off the steady- state, i.e. in a period of reconstruction (for example, after a war). For better comparison with empirical cross-country studies (which usually control for GDP) the policy function $\tau(k)$ is mapped into the tax-income space (using $y=A k^{\alpha}$ ). Both countries start at $y=0.5$, which is a little less than half the steady-state value of the less productive country. At that point both countries

\footnotetext{
${ }_{5}^{5}$ See e.g. Saint-Paul and Verdier (1996), Benabou (2000), Grossmann (2003), Dalgaard et al. (2003). In particular the latter paper is related to the present work because it uses also cross-country productivity differences to explain the inequality-redistribution puzzle. It considers a model without transitional dynamics where more productive countries have a more equal distribution of income. In contrast, the current paper establishes no general productivity-inequality link and explains the puzzle by intersecting policy functions, i.e. as a phenomenon of transitional dynamics.

${ }^{6}$ See, for example, Islam (1995) and Caselli et al. (1996) for the importance country-specific fixed effects.

${ }^{7}$ We consider the case of log-utility and $\alpha=0.36, \rho=0.02, \delta=0.05, \beta=0.2$.
} 
refrain from distribution. Private capital and infrastructure are such scarce that the benefits from high productivity growth over-compensate the benefits from redistribution.

Figure 4. Inequality and Government Size:

A Cross-Country Comparison of Adjustment Dynamics

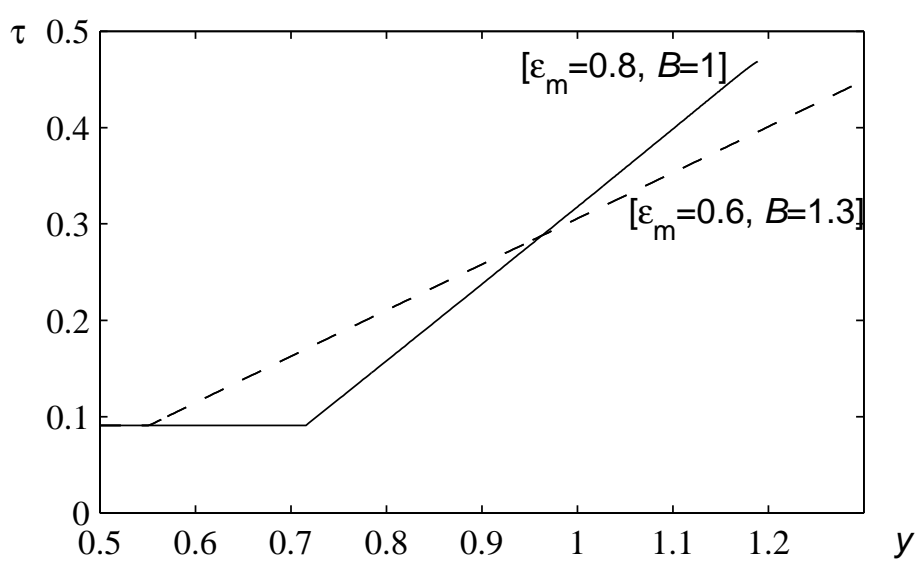

Other parameters: Parameters: $\alpha=0.36, \delta=0.05, \rho=$ $0.02, \beta=0.2$.

At income level $y=0.55$ a welfare-state become achievable in the high-productivity country populated by the poorer median voter, and $\tau$ starts to grow together with income. For a period of time lasting until the point of intersection taxes are higher in the country populated by the more unequal society. We observe a positive partial correlation between income inequality and government size.

As income reaches a level around 0.7 a welfare state becomes affordable in the less productive country populated by the more equal society. In this country, however, productivity growth is relatively slow (because of low TFP) and the opportunity costs of redistribution are comparatively small. For that reason the government has a relatively high incentive to redistribute income in favor of the median voter at any given income level above the lower bound $\bar{\tau}^{*}$. As a consequence of lower opportunity costs of redistribution the slope of the policy function is steeper than in the high productivity country. ${ }^{8}$ After the point of intersection we observe a negative partial correlation between income inequality and government size.

${ }^{8}$ Generally speaking, in phase diagram analysis an increase in general productivity $B$ (and hence $A$ ) reduces the slope of both the $\dot{k}=0$-curve and the $\dot{\tau}=0$ - curve leading to an equilibrium at higher $k$ and a flatter policy function $\tau(k)$. 
Summarizing, the explanation offered for the mixed findings on the inequality-redistribution correlation is based on omitted variables, in particular general factor productivity. The phase diagram analysis has shown that controlling for TFP higher inequality shifts the stable manifold upwards and leads to higher taxes at the steady-state and everywhere along the adjustment path. Hence, controlling for TFP, the implied correlation between inequality and government size is unambiguously positive.

\section{Final Remarks}

The main focus of Meltzer and Richard's work has been the development of government size over the last centuries where an increasing spread of the franchise was observed. While this origin of government growth is still available in the current paper the focus has been on government growth under constant wealth of the median voter. The finding that along the adjustment path the government sector expands although wealth of the median voter remains constant is compatible with Li, Squire and Zou's (1998) observation of an insignificant time trend of inequality for most of the countries contained Deininger and Squire's (1998) dataset during the period 1947-1994; a period characterized by a large expansion of the government sector in many developed countries.

Government growth has been explained as a phenomenon of transitional dynamics, for example, in a period of reconstruction after war or after a structural reform. For that purpose the paper has employed a neoclassical production function. One possible extension could be an explanation of government growth in a model of endogenous growth. For an obvious reason, however, existing median voter models of endogenous growth (e.g. Bertola, 1993, Alesina and Rodrik, 1994) are inappropriate for such an extension. These linear models show no adjustment dynamics while growth of the government sector - although observable over a long period in history - is certainly a temporary phenomenon.

While the government sector continues to grow in many economies, Borcherding et al. (2002) observe falling government consumption over the last decades for the U.S. and some other highly developed European countries. A shrinking government (and in particular a shrinking welfare state) could be explained as a consequence of increasing fiscal policy competition between national authorities. An explanation within the framework presented in this paper could extend the analysis to a two-country model where governments maximize utility of 
their median voters. Using the world capital stock as state variable these government's play Markovian Stackelberg strategies with their median voters and Nash strategies with each other. It is easily imaginable that competition over the world capital stock will lead to less redistributive taxation.

Finally, it is interesting to compare the model's predictions with actual fiscal policy during the period's of reconstruction in West and East Germany, respectively. At different times (after World War II and after German Unification) both region's suffered from massive loss of private and public capital. West Germany's historical path of government growth is explainable within the model provided. The government first refrained from high income redistribution and established a large welfare state at later stages of economic development. With contrast, policy in East Germany with its immediate adoption of West Germany's fiscal system of high taxes and redistribution does not fit the model of maximizing the median voters welfare. Thus, arguments from less formal reasoning that East Germany's fiscal policy has not been in the interest of the East German voter (Sinn, 2000) find support by the theory of government growth offered in this paper. 


\section{Appendix}

Let $u\left(c_{m}(k, \tau(k))\right)$ denote the median voters instantaneous utility function. The solution for problem (5) has to fulfill the tranversality condition (9) and the following first order conditions.

$$
\begin{aligned}
& u^{\prime}\left\{(1-q)-(1-\alpha) \epsilon_{m}+\beta\left[(1-\tau)(1-\alpha) \epsilon_{m} / \tau+(1-q)\right]\right\}+\lambda[(1-\tau) \alpha \beta / \tau-\alpha]=0 \\
& u^{\prime}\left\{-\tau+\beta\left[(1-\tau)(1-\alpha) \epsilon_{m}+(1-q) \tau\right] / q\right\}+\lambda(1-\tau) \alpha \beta / q=0 \\
& u^{\prime}\left[(1-\tau)(1-\alpha) \epsilon_{m}+(1-q) \tau\right] B(q \tau)^{\beta} \alpha k^{\alpha-1} \\
& +\lambda\left[(1-\tau) \alpha B(q \tau)^{\beta} \alpha k^{\alpha-1}-\delta-\frac{\partial c_{k}}{\partial k}\right]=\lambda \rho-\dot{\lambda}
\end{aligned}
$$

Multiplying (A.2) by $q / \tau$ and subtracting the result from (A.1) yields

$$
\lambda=u^{\prime}\left[1-(1-\alpha) \epsilon_{m}\right] / \alpha \Longrightarrow \dot{\lambda}=u^{\prime \prime} c_{m}{ }^{\prime} \dot{k}\left[1-(1-\alpha) \epsilon_{m}\right] / \alpha
$$

Inserting (A.4) in (A.1) provides (6) in the main text.

Inserting $\lambda$ and $\dot{\lambda}$ from (4), and $u^{\prime \prime} / u^{\prime}=-\theta / c_{m}$ from the iso-elastic utility assumption into (A.3) one obtains

$$
-\theta \frac{c_{m}{ }^{\prime}}{c_{m}} \dot{k}=\frac{\alpha^{2}}{1-(1-\alpha) \epsilon_{m}} \frac{c_{m}}{k}+(1-\tau) \alpha B(q \tau)^{\beta} \alpha k^{\alpha-1}-\delta-\rho-\frac{\partial c_{k}}{\partial k}
$$

And inserting the derivative

$$
c_{m}(k, \tau(k))^{\prime}=\alpha \frac{c_{m}}{k}+\left[1-(1-\alpha) \epsilon_{m}\right] \frac{\partial \tau}{\partial k} A k^{\alpha}
$$

and $\partial \tau / \partial k=\dot{\tau} / \dot{k}$ in (A.5) one obtains (7) in the main text.

Finally insert (6) in (4) and substitute the definition of $A$ - now to be found a constant - in order to obtain (8). Equation (9) originates from insertion of (A.4) into the usual transversality condition. 


\section{References}

Alesina, A. and Rodrik, D., 1994, Distributive politics and economic growth, Quarterly Journal of Economics 109, 465-49.

Barro, R.J., 1990, Government Spending in a Simple Model of Endogenous Growth, Journal of Political Economy 98, S.103-S.125.

Barro, R.J. and X. Sala-i-Martin, 1992, Public Finance in Models of Economic Growth, Review of Economic Studies 59, 645-661.

Baumol, W., 1967, Macroeconomics of Unbalanced Growth: The Anatomy of Urban Crisis, American Economic Review 57, 415-426.

Benabou, R., 1996, Inequality and Growth, NBER Working Paper 5658.

Benabou, R., 2000, Unequal Societies: Income Distribution and the Social Contract, American Economic Review 90(1), 96-129.

Bertola, G, 1993, Factor Shares and Savings in Endogenous Growth, American Economic Review 83, 1184-1198.

Borcherding, Th.E., 1985, The Causes of Government Expenditure Growth: A Survey of the U.S. Evidence, Journal of Public Economics 28, 359-382.

Borcherding, Th.E., J.S. Ferris, and A. Garzoni, 2002, Growth and the Real Size of Government Since 1970, in: The Kluwer Handbook of Public Finance, ed. J. Backhaus and R.E. Wagner, Kluwer Academic Press (Hingham, Ma), forthcoming.

Boix, C., 2001, Democracy, Development and the Public Sector, American Journal of Political Science 45, 1-17.

Brunner, M. and H. Strulik, 2002, Solution of Perfect Foresight Saddlepoint Problems: A Simple Method and Applications, Journal of Economic Dynamics and Control 26, 737-753.

Caselli, F., G. Esquivel, and F. Lefort, 1996, Reopening the Convergence Debate: A New Look at Cross-Country Growth Empirics, Journal of Economic Growth 1, 363-389.

Chamley, C., 1986, Optimal Taxation of Capital Income in General Equilibrium with Infinite Lives, Econometrica 54, 607-622.

Dalgaard, C.-J., H. Hansen, and T. Larsen, 2003, Income Skewness, Redistribution and Growth: A Reconciliation, EPRU Working Paper 2003-14, University of Copenhagen.

Deininger, K. and L. Squire, 1998, New Ways of Looking at Old Issues: Inequality and Growth, Journal of Devlopment Economics 57, 259-287.

Grossmann, V., 2003, Income Inequality, Voting over the Size of Public Consumption, and Growth, European Journal of Political Economy 19, 265-287.

Hassler, J., J.V. Rodriguez Mora, K. Storesletten, and F. Zilibotti, 2003, The Survival of the Welfare State, American Economic Review 93(1), 87-112.

Husted, T.A. and L.W. Kenny, 1997, The Effect of the Expansion of the Voting Franchise on the Size of Government, Journal of Political Economy 105(1), 54-82.

Islam, N., 1995, Growth empirics: a panel data approach, Quarterly Jounal of Economics 110, $1127-1170$.

Judd, K.L., 1985, Redistributive Taxation in a Simple Perfect Foresight Model, Journal of Public Economics 28, 59-83. 
Kemp, M.C., N. V. Long, and K. Shimomura, 1993, Cyclical and Noncyclical Redistributive Taxation, International Economic Review 34, 415-429.

Krusell, P., V. Quadrini, and J.-V. Ríos-Rull, 1997, Politico-Economic Equilibrium and Economic Growth, Journal of Economic Dynamics and Control 21, 243-272.

Krusell, P., 2002, Time-Consistent Redistribution, European Economic Review 46, 755-769.

Lansing, K.J., 1999, Optimal Redistributive Capital Taxation in a Neoclassical Growth Model, Journal of Public Economics 73, 423-453.

Li, H., L. Squire, and H. Zou, 1998, Explaining International and Intertemporal Variations in Income Inequality, Economic Journal 108, 26-43.

Meltzer, A.H. and S.F. Richard, 1981, A Rational Theory of the Size of Government, Journal of Political Economy 89, 914-97.

Meltzer, A.H. and S.F. Richard, 1983, Tests of a Rational Theory of the Size of Government, Public Choice 41, 403-418.

Milanovic, B., 2000, The Median-Voter Hypothesis, Income Inequality and Income Redistribution: An Empirical Test with the Required Data, European Journal of Political Economy 16, 367-410.

Perotti, R., 1996, Growth, Income Distribution and Democracy: What the Data Say, Journal of Economic Growth 1, 149-187.

Persson, T. and G. Tabellini, 1994, Is Inequality Harmful for Growth, American Economic Review, 84, 600-621.

Roberts, K.W.S., 1977, Voting over Income Tax Schedules, Journal of Public Economics 8, 329-340.

Romer, Th., 1975, Individual Welfare, Majority Votingm and the Properties of a Linear Income Tax, Journal of Public Economics 4, 163-185.

Saint-Paul, G. and T. Verdier, 1996, Inequality, Redistribution and Growth: A Challenge to the Conventional Political Approach, European Economic Review 40, 719-728.

Sinn, H.-W., 2000, Germany's Economic Unification: An Assessment after Ten Years, Review of International Economics 10, 113-128.

Wagner, A., 1893, Grundlegung der Politischen Oekonomie, Leipzig, 3rd edition. 